Journal of Social Sciences 7 (4): 671-675, 2011

ISSN 1549-3652

(C) 2011 Science Publications

\title{
Bodily Communication in Volleyball and New Data System
}

\author{
Gaetano Raiola \\ Department of Human, Philosophical and Education Sciences, \\ Faculty of Science of Education, University of Salerno, Italy,
}

\begin{abstract}
Problem statement: To verify the incidence of performance analysis data of bodily communication in volleyball and the difference of method gathering data between traditional method and new one. It recognizes the technical skills that are involved in bodily communication aspects. Thus, it analyzes and quantifies three specific technical skills relating the attacker role and the setter one in relationship to defenders: (a) the second ball goes to the opposite court instead of setting for attacking; (b) the attack as fast as possible in the middle of the net; (c) the off speed hit instead of power spike over the block. To establish the difference between the traditional match analysis system and the new one. The methods of this study is complex. The coach trains the performance analyst how to analyze the three technical skills and to whom to attribute exactly the outcomes applying the defined and shared performance indicators. Approach: The analyst directly, that is in real time, recruits the data by hand notation when he observes the match and indirectly, that is in differed time, he recruits the data by using the performance analysis software with slow down and go back mode of the same actions that in hand notation system has just attributed to the bodily communication. The same analyst, by traditional match analysis system, analyzes the data of the same matches by traditional system. It compares the results of the new way performance analysis system and the old way. The sample is 26 matches of volleyball championship of the same team. Results: The results are significant in a new way of gathering data. Innovation bodily communication data system shows the percentage of three technical skills is about $14,5 \%$ for (b) the attack as fast as possible in the middle of the net, $8,5 \%$ (a) the second ball goes to the opposite court instead of setting for attacking and 6,5\% (c) the off speed hit instead of power spike over the block. The percentage for categories of outcomes is $30 \%$ bodily communication, $18 \%$ fundamental outcomes, $17 \%$ adversary errors and $16 \%$ other kind of outcomes and 9\% unknown outcomes. Conclusion: In conclusion the result shows the difference of the data between two performance analysis system and the significance of bodily communication outcomes on the performance. The percentage of bodily communication data is more significant of the other kinds of percentage of data. These data could help the coach to train the team for improving the analyzed technical skills in different mode utilizing this study and so, to create a methodological system training to enhance the performance for every skill.
\end{abstract}

Key words: Anticipate behavior, gathering data system, technical skills, evaluation, performance analysis

\section{INTRODUCTION}

Volleyball is a sport where the use of body language is very frequent, it is a sport with very narrow game space ( 81 square meters per team) and actions extremely rapid and dynamic, whose technical characteristics, tactics and logistics constantly allows nonverbal communication among the players on the court. The players through perceptive and intuitive processing, decode the signs, gestures and facial expression of team-mates and/or of opponents in a few thousandths of a milliseconds through the anticipation and interpretation of the consequences of the actions, one's own or other (each others), confirming the proactive role of the brain that is not restricted to acquire all sensory events of the world, while it interrogates the world according to its conditions in order to predict and anticipate behavior, adjusting the sensitivity, combining messages, pre-specific and values estimated, according to an internal simulation of the expected consequences of the action (Berthoz, 2000).

In particular, the decoding of signs or of facial expressions is "functional" when it refers to the same team and when communication act among players is involved or that one between the trainer and the athletes on the tactical intentions, strategies and the problems of the game. Decoding can be "diagnostic" when it is possible to recognize the different kind of nonverbal 


\section{J. Social Sci., 7 (4): 671-675, 2011}

communications of the opposing team, through signs and elements that characterize the communication styles (Argyle, 1986 and Hall, 1966) of athletes and coaches. The third form of decoding is "tactics" when the gesture or the action simulates a game intention to solicit a reaction of the adversary who helps their own team.

That's why the sensorial information is encoded as motor acts and our motor system is activated as if we carry out actions that we observe, involving the simulation of the same actions and making possible the 'reciprocity' of acts and intentions which is basic for the immediate recognition of the meaning of the gesture of others "as soon as we see someone to perform an act or a chain of acts, its movements, which it wants to or not, it gets an immediate meaning for the observer.

The system of mirror neurons and the selectivity of their answers determines a shared action space, where every act and every chain of acts, our's own or others, are immediately written and understood, without any express or deliberate learning process" (Rizzolatti and Sinigaglia, 2006). Hughes and Franks (2004) suggest that notational analysis is primarily concerned with the analysis of movement, technical and tactical evaluation and statistical compilation. Therefore, the notational analysis is a technique to analyze different aspects of performance through a process which involves a permanent registration of the events. These aspects of a soccer coach's main tasks (i.e., to analyze sports performance: So that feedback) may be given to players immediately and future training sessions must be planned that way. Not surprisingly, the majority of published notational analysis work in sports derives from academics with an interest in soccer, basketball, volleyball and they are not necessarily involved in the coaching process.

Many volleyball coaches do not agree how to attribute the outcome points to the single volleyball fundamentals for all action. That happens when the decision of the attacker attribution and the opposite defender is borderline. Often, the inference of the outcomes in these actions is due to the feint and, generally, by the use of bodily communication in fast motor skills. The exact evaluation of these outcomes, as such as the attribution of the point, could help the coach to analyze the performance of his own athletes and so to train them in the better way).

What tools could be utilized to analyze and evaluate these aspects and the affects of it on the final outcome points? For this study, the purpose is to analyze and quantify three specific skills regarding the attacker role and the setter one in relationship to defender of opposite team: (a) the second ball goes to the opposite court instead of setting for attacking; (b) the attack as fast as possible in the middle of the net; (c) the off speed hit instead of power spike over the block.

Finally, to establish the difference between the traditional match analysis system and the new one, it recruits the data in a different way to verify the incidence of performance analysis data on bodily communication in volleyball. Furthermore, the difference of method gathering data between the traditional method and the new one. It analyzes and quantifies three specific skills relating the attacker role and the setter one in relationship to defenders: (a) the second ball goes to the opposite court instead of setting for attacking; (b) the attack as fast as possible in the middle of the net; (c) the off speed hit instead of power spike over the block. To establish the difference between the traditional match analysis system and the new one. The aim of this study is to verify the incidence of performance analysis data of bodily communication in volleyball and the difference between the traditional and the new one method of gathering data.

It recognizes the principal skills that are involved in bodily communication aspects. Thus, it analyzes and quantifies three specific skills relating to the attacker role and the setter one in relationship to defenders: (a) the second ball goes to the opposite court instead of setting for attacking; (b) the attack as fast as possible in the middle of the net; (c) the off speed hit instead of power spike over the block. To establish the difference between the traditional match analysis system and the new one.

The aspects of non-verbal communication in volleyball, its codes and the technical and tactical usage of gesture, are the result of the meeting between tacit and implied dimension that comes from experience gained on the range of activities and a theoretical dimension that scientifically characterizes and justifies the expressive and communicative potential of body.

The scientific aims of this research work are:

- To define a first inventory of signs used more frequently in volleyball according to the principles of bodily communication (Argyle, 1988) the aspects of perceptive senses (Berthoz, 2000) and the neurobiological implications (Rizzolatti and Sinigaglia, 2006)

- To give a general plan for training that includes knowledge about the function of gestures, signs and mimicking, the structure and the mean of nonverbal messages and the effects of bodily communication on behavior in order to build expressive and communicative skills of volleyball coach of the signs and the gesticulation in 
communication processes and in particular the "pragmatic" side of communication and the effects that it has on behavior (Watzlawick et al., 1967)

The paths of training for team sports coaches reflect the guidelines of studies and research on the methodology of the training of volleyball focused on the improvement of functional aspects, on the development of conditional abilities and energy mechanisms and on optimization of the bio-mechanical aspects, undervaluing the function of bodily communication during the game through the gestures, the signs and the mimicking.

This trend produces a basic formation of sports operators providing skills on the theory of training, tactics and schemes of games, the knowledge of biomechanics and automatic technical-sport gestures, functional mechanisms to recruit energy, psychological bases that regulate the action team during phases of game, but doesn't deal with the function The information derived from this type of computerized system can be used for several purposes as suggested by Hughes and Franks (2004):

- Immediate feedback

- Development of a database

- Indication of areas requiring improvement

- Evaluation

- As a mechanism for selective searching through a video recording of the game

All of the above functions are of paramount importance to the coaching process, the initial reason of notational analysis. The development of a data-base is a crucial element, since it is sometimes possible, if the data-base is large enough, to formulate predictive models as an aid to the analysis of different sports, subsequently enhancing future training and performance.

\section{MATERIALS AND METHODS}

The coach of the selected team trains the performance analyst how to analyze three fast skills and to whom exactly to attribute the outcomes between the attacker of his own team and defender of the opposite team applying the different performance indicators.

The analysis is in real time that is the recruitment of data is directly by hand notation when the analyst observes the match and in differed time, that is the analyst recruits data when by using the performance analysis software with slow down and go back mode.
Furthermore, the same analyst, by traditional match analysis system, analyzes the data of the same matches in the traditional and actual manner. Finally, it compares the results of the new way performance analysis system and the old way using the match analysis system the sample is 26 matches of volleyball championship of the same team.

\section{RESULTS}

Innovation bodily communication data system shows the percentage of three skills is about $14,5 \%$ for b) the attack as fast as possible in the middle of the net, $8,5 \%$ (a) the second ball goes to the opposite court instead of setting for attacking and 6,5\% (c) the off speed hit instead of power spike over the block (Fig. 1). The percentage for categories of outcomes is $30 \%$ bodily communication, $18 \%$ fundamental outcomes, $17 \%$ adversary errors and $16 \%$ other kind of outcomes and $9 \%$ unknown outcomes (Fig. 2).

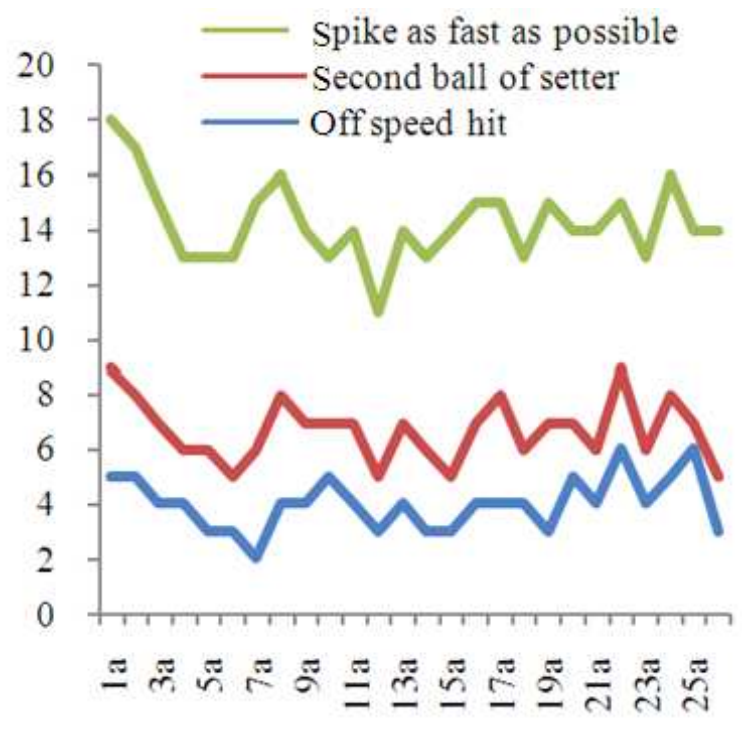

Figure 1: Graphic data bodily communication outcomes

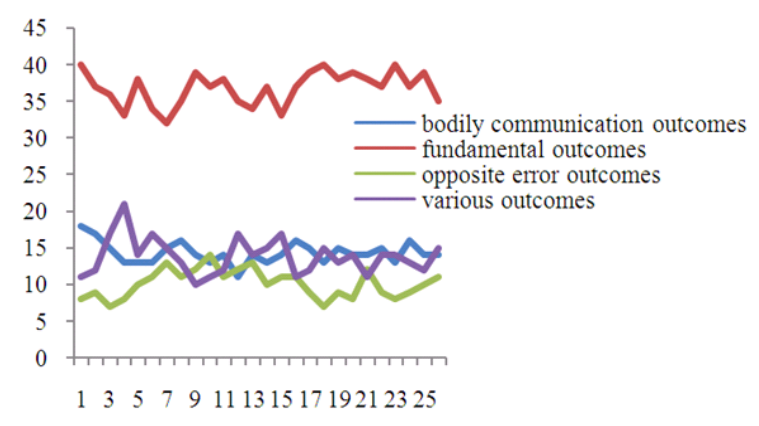

Figure 2: Graphic data gathering of kinds of outcomes 
Table1 Data bodily communication outcomes

\begin{tabular}{llll}
\hline Matches & $\begin{array}{l}\text { Off speed } \\
\text { hit }\end{array}$ & $\begin{array}{l}\text { Second ball } \\
\text { of setter }\end{array}$ & $\begin{array}{l}\text { Spike as fast } \\
\text { as possible }\end{array}$ \\
\hline 1 & 5 & 4 & 9 \\
2 & 5 & 3 & 9 \\
3 & 4 & 3 & 8 \\
4 & 4 & 2 & 7 \\
5 & 3 & 3 & 7 \\
6 & 3 & 2 & 8 \\
7 & 2 & 4 & 9 \\
8 & 4 & 4 & 8 \\
9 & 4 & 3 & 7 \\
10 & 5 & 2 & 6 \\
11 & 4 & 3 & 7 \\
12 & 3 & 2 & 6 \\
13 & 4 & 3 & 7 \\
14 & 3 & 3 & 7 \\
15 & 3 & 2 & 9 \\
16 & 4 & 3 & 8 \\
17 & 4 & 4 & 7 \\
18 & 4 & 2 & 7 \\
19 & 3 & 4 & 8 \\
20 & 5 & 2 & 7 \\
21 & 4 & 2 & 8 \\
22 & 6 & 3 & 6 \\
23 & 4 & 2 & 7 \\
24 & 5 & 3 & 8 \\
25 & 6 & 1 & 7 \\
26 & 3 & 2 & 9 \\
\hline
\end{tabular}

Table 2 Data gathering of kinds of outcomes

\begin{tabular}{lllll}
\hline Matches & $\begin{array}{l}\text { Bodily communication } \\
\text { outcomes }\end{array}$ & $\begin{array}{l}\text { Fundamental } \\
\text { outcomes }\end{array}$ & $\begin{array}{l}\text { Opposite error } \\
\text { outcomes }\end{array}$ & $\begin{array}{l}\text { Various } \\
\text { outcomes }\end{array}$ \\
\hline 1 & 18 & 40 & 8 & 11 \\
2 & 17 & 37 & 9 & 12 \\
3 & 15 & 36 & 7 & 17 \\
4 & 13 & 33 & 8 & 21 \\
5 & 13 & 38 & 10 & 14 \\
6 & 13 & 34 & 11 & 17 \\
7 & 15 & 32 & 13 & 15 \\
8 & 16 & 35 & 11 & 13 \\
9 & 14 & 39 & 12 & 10 \\
10 & 13 & 37 & 14 & 11 \\
11 & 14 & 38 & 11 & 12 \\
12 & 11 & 35 & 12 & 17 \\
13 & 14 & 34 & 13 & 14 \\
14 & 13 & 37 & 10 & 15 \\
15 & 14 & 33 & 11 & 17 \\
16 & 16 & 37 & 11 & 11 \\
17 & 15 & 39 & 9 & 12 \\
18 & 13 & 40 & 7 & 15 \\
19 & 15 & 38 & 9 & 13 \\
20 & 14 & 39 & 8 & 14 \\
21 & 14 & 38 & 12 & 11 \\
22 & 15 & 37 & 9 & 14 \\
23 & 13 & 40 & 8 & 14 \\
24 & 16 & 37 & 9 & 13 \\
25 & 14 & 39 & 10 & 12 \\
26 & 14 & 35 & 11 & 15 \\
\hline
\end{tabular}

It shows the difference of data between two performance analysis systems and the significance of bodily communication outcomes on the performance (Table 1).

The percentage of bodily communication data is more significant of the other kinds of percentage of data collection (Table 2).
The 26 matches are enough to examine the new way of collection data and to deep the relation between the new one and the old one throughout an integrated process of collection to extrapolate every data to give to coach. The attribution of outcomes for every player is useful to investigate on another purpose regarding the performance for athletes to play in these skills.

\section{DISCUSSION}

Four major purposes of notation have been delineated. They are:

\section{- Analysis of movement \\ - Tactical evaluation \\ - Technical evaluation \\ - Statistical compilation}

Team sports have the potential to benefit immensely from the development of computerized notation. The sophistication of data manipulation procedures available can aid the coach in their efforts to ameliorate performance. Many of the traditional systems outlined above are concerned with the statistical analysis of events which previously had to be recorded by hand. The advent of on-line computer facilities overcame this problem, since the game could then be digitally represented first, via data collection directly onto the computer and then later documented via the response to queries pertaining to the game.

The result shows the difference of data between two performance analysis systems and the significance of bodily communication outcomes on the performance. The percentage of bodily communication data is more significant of the other kinds of data percentage. These data could help the coach to train the team for improving the analysis of skills in different mode utilizing this study and so, to create a methodological system training to include these aspects.

The field of performance analysis in general has expanded and progressed greatly over the last 20 years. As with most things, technology and research have leaded the way in terms of development, particularly for notation analysis systems.

Currently, the most advanced systems may be desirable but the cost is likely to be prohibitive to all but the wealthiest and by logical extension successful sports teams.

The main development over the last 10 years has been the lowering cost of computers and video cameras which has led to the formation of a number of companies selling specialist software for different types of performance analysis. Currently most sports teams 
and individuals can afford the equipment necessary to record and analyze their performances. However, having the equipment and using it effectively is not necessarily the same thing. Over the next 10 years it is likely that the process of analyzing performances will become significantly easier.

This is likely to be achieved in the software with the use of some form of interactive help whilst also removing the need to have a degree in computer programming, statistics and artificial intelligence. Also with the growing popularity of notation analysis in professional sport so is the need to adequately educate sports scientists in this area. Currently, many universities have teaching and research programs in place with others developing courses and the expertise to meet the demand. This demand will strengthen notational analysis as a discipline leading to better research by way of methodological advances, more appropriate statistical procedures and simpler output formats. These advances will in turn be fed back into sports organizations and companies to the benefit of all prospective notation analysts.

Therefore, it is necessary to provide an educational course for technicians and coaches that teaches and speaks about the following subjects:

- Neurobiological knowledge on the mechanisms of regulation of the various types and ways of imitation, learning and gestural communication according to the research on mirror neurons (Rizzolatti and Sinigaglia, 2006)

- Knowledge of the mechanisms of perception and on the sense of movement or kinaesthesia which makes possible of simulations and anticipations of motor actions (Berthoz, 2000)

- Knowledge of the mechanisms of imitation in the different phases of training

- Acquaintance and meaning of non-verbal communication, of the interpersonal motor attitudes, of posture, of facial expressions, of contact, of walk and of the glance (Argyle, 1988)

\section{CONCLUSION}

Biomechanics plays an important role in optimizing the training quality in elite sport. The areas of applying biomechanics in the training process of elite athletes are very diverse. In the first area, those parameters which essentially influence performance have to be analyzed. These investigations have to be done during field studies using highly developed kinematic, kinetic measurement systems. The scientific challenges lie in the precision of the parameters determined (accuracy of the measurement system) and in the fact that the athlete should not be interfered severely by the measurement system during performance. The results of such investigations lead to a better understanding of movements used and provide coaches and athletes valuable support in directing training goals.

The efficiency of the training process also depends on the quality of performance tests available. Standardized tests should be built into the trainings process for all performance-relevant features. These tests must satisfy the criteria of objectivity, reliability and validity. In recent year's specific test batteries using various high tech measurement devices has successfully been developed.

\section{REFERENCES}

Argyle, M., 1988. Bodily Communication. 2nd Edn., Taylor and Francis, Madison, ISBN: 0416381502, pp: 363

Berthoz, A., 2000. The Brain's Sense of Movement. 1st Edn., Harvard University Press, Cambridge, ISBN: 0674009800, pp: 337.

Hall, E.T., 1966. The Hidden Dimension. 1st Edn., Garden Peter Smith Pub, Gloucester, ISBN: 0844665525, pp: 217.

Rizzolatti, G. and C. Sinigaglia, 2006. So Quel che Fai. Il Cervello che Agisce e i Neuroni Specchio. 1st Edn., R. Cortina, Milano, ISBN: 8860300029, pp: 216.

Hughes, M. and I.M. Franks, 2004. Notational Analysis of Sport: Systems for Better Coaching and Performance in Sport. 2nd Edn., Routledge, London, ISBN: 041529004X, pp: 304.

Watzlawick, P., J.B. Beavin and D.D. Jackson, 1967. Pragmatics of Human Communication: A Study of Interactional Patterns, Pathologies and Paradoxes. 1st Edn., W W Norton and Co Inc., New York, ISBN: 0393707075, pp: 304. 